\title{
Lendo Zora Hurston: a obra Mules and Men e sua relação com a teoria e a história da antropologia
}

\author{
TELMA DE SOUSA BEMERGuY (iD \\ Universidade Federal do Rio de Janeiro | Rio de Janeiro, RJ Brasil \\ tsbemerguy@gmail.com
}

DOI 10.11606/issn.2316-9133.v30i1pe183139

\begin{abstract}
resumo Aproximando-me de iniciativas que têm buscado tensionar os processos excludentes que permeiam a fixidez irrepreensível dos cânones antropológicos, proponho nesse ensaio, proponho um caminho alternativo ao quadro de leituras branco e masculino que usualmente caracteriza os primeiros anos de contato com a teoria antropológica na universidade. Apresento uma leitura sobre a obra Mules and Men de Zora Hurston - intelectual negra estadunidense e aluna pouco lembrada de Franz Boas, "pai” da antropologia cultural norteamericana. Partindo da disputa em torno da classificação do livro ao longo do tempo, busco indicar a forma como a obra dialogou com as teorias em voga no período, recuperando eventos e debates que nos permitirão visualizar como o trabalho de Zora Hurston acabou sendo pouco reconhecido pelos antropólogos da época, resultando em um longo período de apagamento de suas contribuições à disciplina.
\end{abstract}

palavras-chave Zorah Hurston. Antropologia Cultural. História da Antropologia

Reading Zora Hurston: Mules and Men and its relation with the story and theory of Anthropology

abstract This essay proposes an alternative pathway to the white and male reading frame that usually characterizes the first years of contact with anthropological theory in Brazilian universities. In so doing, it presents an overview of Mules and Men by Zora Hurston - an Afro-American intellectual and a less-recognized student of Franz Boas, the "father" of American cultural anthropology. Additionally, it analyses how the work was related to theories in vogue in his epoch while explores the disputes over its classification since its first edition. Recovering events and debates about these themes will allow us to understand better how Zora Hurston's work ended up being barely known by contemporary anthropologists, resulting in a long period of silence about her contributions to the discipline. 
keywords Zora Hurston. Cultural Anthropology. History of Anthropology

\section{Leyendo a Zora Hurston: Mules and Men y su relación con la historia y teoría de la antropología:}

resumen Hay un conjunto reciente de iniciativas que han buscado tensar los procesos excluyentes que permean la irreprimible fijeza de los cánones antropológicos. Ante esto, este ensayo propone un camino alternativo a las lecturas blancas y masculinas que suelen caracterizar los primeros años de contacto con la teoría antropológica en la universidad. Les presento una lectura sobre la obra Mules and Men, de Zora Hurston, intelectual afroamericana y estudiante de Franz Boas, "padre" de la antropología cultural norteamericana, aunque ella sea poco recordada. Partiendo de la disputa por la clasificación del libro en el tiempo, en el artículo busco señalar cómo la obra dialogó con las teorías en boga en ese momento, recuperando hechos y debates que nos permitirán visualizar cómo la obra de Zora Hurston terminó siendo poco. reconocido por los antropólogos de la época, resultando en un largo período de borrado de sus aportes a la disciplina.

palabras clave Zora Hurston. Antropología Cultural. Historia de la antropología.

\section{Introdução}

Ainda no início de nossa formação enquanto antropólogos, quando somos provocados a refletir sobre os temas "clássicos" da disciplina e a estudar e compreender o processo de consolidação da Antropologia enquanto uma ciência autônoma, comumente, somos conduzidos a uma lista de referências "incontornáveis" que transformam os primeiros anos de contato com a teoria antropológica em um longo período de leituras de trabalhos produzidos por antropólogos brancos - homens, em sua imensa maioria. Indo de encontro a iniciativas que têm buscado tencionar os processos excludentes que permeiam a solidez irrepreensível dos cânones antropológicos (Böschemeier et al, 2020), colocando em evidência a "necessidade de uma revisão profunda dos currículos e dos clássicos da antropologia”(Hurston, 2019; Basques, 2019) abordados no Brasil, proponho nesse ensaio um caminho alternativo ao quadro de leituras embranquecido e masculino acerca de um dos períodos formativos da disciplina, apresentando uma reflexão sobre alguns elementos da obra de Zora Hurston, escritora e intelectual negra estadunidense, a quem, durante muito tempo, foi negado o reconhecimento devido por seus trabalhos realizados enquanto antropóloga. Apesar de ter se tornado mais conhecida por seus escritos como romancista, em um certo período de sua trajetória, a autora teve Franz Boas como orientador e professor, antropólogo considerado por muitos o pai da Antropologia Cultural norte-americana. A partir de desdobramentos de sua relação de orientação com Boas, Hurston conduziu diversas pesquisas nesse período de institucionalização da antropologia no país. Em uma delas, na década de 20, dedicou-se a conduzir um "trabalho de coleta de folclore dos negros" 
no sul dos Estados Unidos, o qual resultou no livro que analisarei mais detidamente nesse ensaio: Mules and Men, publicado em 1935.

Para mim, diferentes elementos podem ser abordados a partir da leitura que realizamos de uma determinada obra, na medida em que podemos esquadrinhá-la ora em função de uma análise dos conceitos e das perspectivas teóricas que a perpassam, ora em função dos eventos, conflitos e disputas que marcaram o campo e a vida de um/a autor/a em um determinado contexto histórico. Nesse ensaio, buscarei construir um diálogo com a obra Mules and Men que possa ser informativo tanto de elementos da teoria, quanto da história de Zora Hurston e da antropologia. Tal como destacou Foucault (2005), acredito que seja impossível dissociar a discussão sobre a produção de saberes científicos de reflexões sobre os mecanismos de poder que definem aquilo que é entendido e reconhecido enquanto tal. Ler uma obra sem perder de vista a trajetória de seus autores e os contextos em que as produziram, a meu ver é uma forma de colocar em evidência processos de legitimação e as relações de poder que movimentaram.

Seguindo às reflexões de Dell Hymes (1974), penso que refletir sobre o que foi definido enquanto um trabalho antropológico em um determinado contexto é tão revelador para a história da disciplina quanto refletir sobre aquilo que não foi caracterizado como tal no mesmo contexto. Essa luta de classificações certamente se relaciona com o processo de institucionalização da antropologia enquanto uma disciplina e com todo o jogo de forças envolvido na definição de um campo científico autônomo (Foucault, 2005; Bourdieu, 1983). E como todo campo é um campo de forças e de lutas para conservar ou transformar esse campo de forças (Bourdieu, 1983), creio que alguns debates em torno da obra de Hurston são exemplares das disputas envolvidas na caracterização daquilo que se define ou não enquanto ciência, ou que se definiu ou não como Antropologia ao longo do tempo. Nesse sentido, abordo então como o livro Mules and Men pode oferecer um caminho para acessarmos, desde outro lugar, escritos que reverberam debates considerados clássicos na disciplina.

Tem recaído sobre esse livro em particular uma longa disputa em torno de sua classificação. Publicado por Zora Hurston em 1935, o livro foi construído a partir do resultado do trabalho de "coleta de folclore" realizado pela autora entre 1927 e 1928 em várias cidades do sul dos Estados Unidos, sendo uma delas a cidade em que cresceu, Eatonville. Na época, Franz Boas, prefaciando a obra, a caracterizou como um trabalho sobre o "folclore dos negros". Ainda que o prefácio do antropólogo tenha trazido à obra certa credibilidade para que fosse reconhecida como um "legítimo trabalho acadêmico" (Cotera, 2021), Boxwell (1992) destaca, por outro lado, como os críticos homens contemporâneos à época sugeriram, pejorativamente, que Mules and Men era muito mais ficção do que ciência social. Anos após sua publicação, a classificação da obra continuaria a ser objeto de disputa.

Pouco reconhecida ao longo da vida, Zora Hurston morreu aos 69 anos, em 1960, e foi enterrada em um túmulo sem identificação. Em 1975, Alice Walker, outra importante escritora 
afro-americana, publica um artigo descrevendo sua busca pelo túmulo de Zora, trazendo a público um pouco de sua história e consagrando-a como a referência que mais influenciou seu trabalho. ${ }^{1}$ A partir da homenagem de Walker (1975), iniciou-se um movimento de releitura dos escritos de Hurston que culminou em reivindicações de maior reconhecimento ao trabalho da autora. Assim, seu livro Their eyes were watching God, publicado em 1937, passou a ser reconhecido como a primeira obra feminista publicada por uma mulher negra nos Estados Unidos e o livro Mules and Men foi reivindicado como a primeira obra de Antropologia publicada por uma mulher negra no país (Boxwell, 1992; hooks, 1990).

Partindo da disputa em torno da caracterização da obra Mules and Men ao longo do tempo, apresentarei o livro buscando apontar caminhos para que possamos vislumbrar o que, no contexto de sua publicação - tanto no campo da teoria, como no campo da história determinou sua caracterização enquanto uma produção folclórica, um escrito de "ficção", e não enquanto uma obra de Antropologia, como passaria a ser reivindicado, décadas depois. Buscando situar como a obra não estava desconectada dos debates antropológicos da época, apresentarei a proposta teórica da antropologia de Boas, apontando como a perspectiva teórica do autor atravessou a realização do trabalho de campo de Hurston, tanto a partir do que a autora fez, como do que deixou de fazer.

Atentando para o fato de que, apesar de algumas iniciativas recentes de divulgação da produção de Hurston, a obra da autora segue sendo ainda pouco conhecida no Brasil ${ }^{2}$, irei me

\footnotetext{
${ }^{1}$ Nascida em 1944, Alice Walker é uma escritora, feminista e poetisa negra estadunidense. É autora da premiada obra "A Cor Púrpura", pelo qual recebeu o National Book Awards e o Prêmio Pulitzer de ficção. Mais informações sobre sua obra e trajetória estão disponíveis no link: https://www.geledes.org.br/hoje-na-historia-9-de-fevereirode-1944-nascia-alice-walker/ acesso em 08 de março de 2021.

${ }^{2}$ Há ainda pouca produção publicada sobre Zora Hurston no Brasil, sobretudo no que se refere aos seus trabalhos enquanto antropóloga. Há alguns trabalhos sobre outras dimensões de sua obra e trajetória, sobretudo sobre seus escritos enquanto romancista, como, por exemplo, em Gomes (2004), Silva (2011), Veronesi e Silva (2015), Lourenço (2019) e Wobeto (2020). Seu romance de maior sucesso, "Their eyes were watching God" [Seus olhos viam Deus] foi traduzido para o português tardiamente, em 2002, e apenas mais recentemente, em 2019, outro pequeno ensaio da autora - onde podemos acessar um pouco sobre suas percepções acerca de seu próprio trabalho - foi traduzido (Hurston, 2019; Basques, 2019). Em busca de mudar esse quadro, desde 2019, o projeto de extensão RECânone, coordenado pela professora Ana Gretel Echazú, na Universidade do Rio grande do Norte, tem trabalhado para realizar traduções da obra de Hurston, defendendo que processos tradutórios são essenciais para ampliar lugares de fala na antropologia. Mais informações sobre o projeto, o processo de escolha dos textos e a motivação por traduzi-los, podem ser encontradas em Böschemeier. et al (2020). Outras importantes iniciativas de divulgação do trabalho de Hurston no Brasil têm se dado a partir do universo dos podcasts de antropologia. Em 2020, o podcast "Conversas da kata" apresentou um episódio dedicado à autora, tratando sobre seus trabalhos e da importância de sua obra para discentes negros do departamento de antropologia da UnB (Ramos et al, 2020). Recentemente, em 2021, o podcast "Campo" lançou um episódio abordando a obra de Hurston e apresentando sua trajetória no campo da antropologia (Lacerda; Parreiras, 2021). No momento da finalização da escrita deste texto, as traduções de textos de e sobre Zora Hurston haviam sido publicadas em uma edição especial da Ayé: Revista de
} 
dedicar inicialmente a uma descrição mais detalhada de sua biografia, a partir da qual procurarei abordar sinteticamente o contexto de segregação racial nos Estados Unidos e a luta por direitos civis e igualdade racial naquele período. Um ponto fundamental para que possamos entender a obra e a trajetória de Hurston, os debates vigentes na antropologia da época e a forma como seus escritos foram recebidos.

\section{Zora Hurston: a rainha do Harlem ${ }^{3}$}

Zora Neale Hurston nasceu na cidade de Notasulga no estado do Alabama, no dia 7 de janeiro de 1891. Ainda quando criança, mudou-se com a família para a cidade de Eatonville no estado da Flórida. Ela era a quinta de uma família de oito filhos, filha de John Hurston e Lucy Hurston, um carpinteiro e pastor da Igreja Batista e uma ex-professora de escola. Quando Hurston tinha apenas 13 anos, a morte prematura de sua mãe definiu a necessidade em buscar novos caminhos. A partir daí passou a enfrentar uma série de problemas familiares que a impediram de concluir seus estudos básicos. Somente no ano de 1917, quando se mudou para cidade de Baltimore, localizada no estado de Maryland, já com 26 anos de idade, Hurston conseguiu retornar ao colégio para terminar o ensino médio. Em seguida, em 1919, Hurston foi aceita na Universidade de Howard, localizada em Washington DC, capital do país, também no estado de Maryland, em sua fronteira com o estado da Virgínia. Em um país marcado por leis de segregação racial, a Universidade de Howard era uma instituição voltada principalmente para população negra e outros grupos racializados, como pessoas de ascendência asiática e indígenas. E ali com 28 anos de idade, ela começou a escrever (Jump at the Sun, 2008).

Em Howard, ela conheceu Alain Locke, "um filósofo que acreditava que os artistas negros estavam se tornando uma nova classe cultural na América” (Jump at the Sun, 2008). Foi pelo incentivo de Locke que Hurston se mudou para o lugar que estava se tornando o centro da produção cultural afro-americana na época: o Harlem, na cidade de Nova York (Jump At The Sun, 2008). Em sua autobiografia, ela conta que "na primeira semana de janeiro do ano de 1925,

\footnotetext{
Antropologia. O volume especial pode ser acessado em <https://revistas.unilab.edu.br/index.php/ Antropologia/issue/view/33>. Acesso em 08-jul-2021.

${ }^{3}$ Parte das informações utilizadas para a construção dessa seção sobre a vida da autora foram encontradas no site oficial da vida de Zora Hurston, na sessão “About Zora Neale Hurston” escrita por Valerie Boyd, autora do livro Wrapped in the rainbows: the life of Zora Neale Hurston”. Na página é possível acessar um grande volume de dados sobre sua vida e obra. Link: https://www.zoranealehurston.com. Acesso em 10 de março de 2021.

${ }^{4}$ Alain Locke, considerado por muitos como o pai do Renaissance Harlem. The New Negro foi um livro editado por ele e reunindo escritos de intelectuais da juventude do Harlem, sendo assim considerado um marco. A obra contribuiu para que a expressão The New Negro se tornasse uma referência ao espírito da luta afro-americana da época. A expressão representava uma referência às novas gerações que resistiam no pós-abolição, buscando transformar os estereótipos racistas dirigidos a eles, falando por si e se autoafirmando, através das artes, da literatura
} 
chegou a Nova York com um dólar e cinquenta no bolso, sem emprego, sem amigos e cheia de esperanças" (Hurston, 2010 [1942]: 126). ${ }^{5}$

Caracterizado por lideranças do movimento negro da época como a capital negra da nação, o Harlem dos anos 20 que Hurston conheceu estava marcado pela luta dos movimentos políticos afro-americanos para promover a autoafirmação da população negra estadunidense e a luta pela garantia dos direitos civis que ainda lhes eram negados. Esse quadro de efervescência cultural e política ficaria conhecido como o Renascimento do Harlem (McKay, 1940). Haviam se passado cinquenta cinco anos desde a vitória do Norte abolicionista sob o sul escravista na Guerra Civil nos Estados Unidos (1861-1865), mas a legislação “Jim Crown” de segregação racial, mantida sobretudo nos estados do sul do país, continuava a afetar violentamente a população negra do país. ${ }^{6}$ Grande parte dos moradores do Harlem vinha dessas áreas, fugindo da violência e da segregação. ${ }^{7}$ Toda essa efervescência política em torno da tensão racial existente no país fez do Harlem um espaço emblemático de contestação e transformação no início do século XX. E foi a importância do Harlem naquele período que acabou por mediar o interesse de Franz Boas pelo trabalho de Hurston (Cotera, 2021). Pois afinal de contas, como relata Valerie Boyd - outra biógrafa de Hurston -, Zora se autoproclamava a rainha do Harlem (Jump at the Sun, 2008).

Ainda no ano de 1925, a escritora conseguiu uma bolsa de estudos para estudar na Universidade de Barnard, em Nova York, instituição irmã da Universidade de Columbia, onde Hurston seria a primeira aluna negra e teria Franz Boas como orientador (Jump at the Sun,

e da valorização da cultura popular negra. Para mais informações sobre o Harlem Renaissance e a influência de Alain Locke no período, ver Rampersard (1997) e Stewart (2018).

${ }^{5}$ Todas as traduções apresentadas no texto são traduções livres feitas pela própria autora, exceto os textos usados em suas versões com tradução oficial, conforme lista de referências bibliográficas ao fim.

${ }^{6}$ No sistema político norte-americano, os Estados mantêm maior independência e maior raio de ação na definição de legislações à nível estadual, o que, ainda hoje, torna possível que haja orientações legais distintas relacionados aos direitos das populações afro-americanas no país. No início do século XX, conforme destaca Kousser (2003), as legislações estaduais no marco "Jim Crow" definiam uma série de medidas de segregação que poderiam ser mais ou menos abrangentes conforme o estado. As medidas tratavam, dentre outras coisas, de constituir escolas separadas para negros e brancos, de restrições ao direito da população afro-americana ao voto, de promover a segregação em espaços públicos, meios de transporte, banheiros, restaurantes e bares e ainda tratavam de definir a ilegalidade de casamentos interraciais. Nos estados do sul, região que defendeu a manutenção da escravidão no contexto da guerra civil que tomou o país no final do século XIX, a legislação "Jim Crown” e a violência racial foram muito mais severas no pós-guerra, quadro que, segundo Kousser (2003), somente sofreria transformações significativas a partir de 1964, com a promulgação do Civil Right Acts, uma conquista da luta do movimento negro norte-americano.

${ }^{7}$ Informação disponível na página https://www.ushistory.org/ no verbete "Harlem Renaissance". Acesso em 8 de março de 2021. 
2008). No ano seguinte, em 1926 , ela realizaria trabalho de campo na região do Harlem ${ }^{8}$ sob supervisão de Franz Boas, dando corpo a uma relação de trabalho ambivalente que, conforme veremos ao longo do texto, seria objeto de inúmeras críticas, anos depois. Mas voltando aos eventos do período, Zora conta em sua autobiografia como ficou orgulhosa quando, duas semanas antes de encerrar seus estudos em antropologia na universidade, "Papa Franz", "o maior antropólogo vivo de sua época”, arranjou uma bolsa de estudos para que ela pudesse ir ao sul do país fazer pesquisas sobre o folclore dos negros (Hurston, 2010 [1942]: 2021).

Mas ainda não seria essa a viagem em que a autora teria sucesso em sua coleta do folclore: sua primeira experiência de trabalho de campo é considerada por ela mesma como uma decepção (Hurston, 2010 [1942]). ${ }^{9}$ Contudo, ela destaca que as razões de sua falha não foram ocasionadas por sua "falta de talento para a realização de pesquisa". Hurston considera que o seu erro foi na forma da abordagem, pois o "glamour de Bannard ainda estava sobre ela", o que determinou que as pessoas de quem tentava se aproximar negassem saber das histórias que ela buscava, intimidadas pelo seu jeito de falar e pelo seu sotaque acentuado do Norte (Hurston, 2010 [1942]). Boxwell (1992) sugere que a percepção da autora sobre a importância da abordagem marcou profundamente a maneira como decidiu conduzir sua segunda viagem a campo, aquela que resultaria na publicação de Mules and Men. Ao longo da obra é possível perceber que a autora conduz o trabalho de campo consciente da necessidade de estratégias de aproximação. Hurston se preocupava com o treinamento recebido em sua formação com Boas, principalmente no que dizia respeito à preocupação do antropólogo com a objetividade na condução do trabalho. Mas sua primeira incursão a campo lhe mostrou que a aposta no distanciamento determinou seu fracasso. Em sua volta ao sul do país (e depois, novamente, quando constrói sua narrativa) ela assume os riscos, e passou a jogar com o uso da objetividade. Por um lado, trazendo-a para afirmar a legitimidade de seu olhar, por outro deixando-a de lado.

\section{Os "óculos de espião da Antropologia" e as estratégias de aproximação}

O livro Mules and Men se divide em duas partes: a primeira, nomeada de "contos folclóricos”, possui dez capítulos e é construída a partir dos trabalhos de coleta feitos por Hurston nas cidades de Eatonville, Loughman, Pierce e Lakeland - todas localizadas no estado da Flórida. A segunda parte, por sua vez, denominada de "Hoodoo", possui sete capítulos e é dedicada a exposição de material relacionado especificamente ao tema do Vodu, fruto de

\footnotetext{
${ }^{8}$ Informação disponível na cronologia sobre a vida de Hurston disponibilizada no apêndice do livro Mules and Men. Segundo Cotera (2021), o trabalho consistiu em medir crânios no Harlem de modo a reunir dados para contestar as teorias da época sobre a inferioridade racial dos negros.

${ }^{9}$ Mais detalhes sobre os desafios, as fontes de financiamento e o processo de planejamento e realização dessa viagem de campo "fracassado" e sobre a realizada posteriormente, dando origem ao livro Mules and Men, podem ser encontradas em Cotera (2021.)
} 
trabalho de campo realizado em Nova Orleans, no estado de Louisiana. Os capítulos não possuem títulos temáticos. Há, em cada um deles, apenas uma listagem do título das diferentes histórias coletadas. Nessa seção, me dedicarei a análise de alguns elementos relativos à primeira parte da obra, onde a autora recupera com mais detalhes o processo de construção da pesquisa. Ainda na Introdução, falando mais especificamente sobre o trabalho de coleta dos contos folclóricos, a autora deixa claro que a escolha do local para a realização da pesquisa não foi feita de maneira aleatória. Ela conta que:

Dr. Boas me perguntou onde eu queria realizar o trabalho e eu disse, 'Flórida', e apresentei a ele meu grande motivo: 'a Flórida é um lugar que atrai pessoas - brancos de todo o mundo, negros de todos os estados do sul e certamente e alguns outros do Norte e do Oeste'. Então eu sabia que era possível obter uma visão transversal do Sul Negro em um único Estado. (Hurston, 2008 [1935]: 1 , tradução livre) $)^{10}$

É possível considerar que a escolha do local evidencia às preocupações metodológicas de Boas no trabalho empírico de coleta: um território geográfico pequeno e bem definido (Boas, 2004a: 34), que pelas particularidades da história de sua ocupação seria considerado representativo de toda uma área cultural. Pela descrição de Hurston sobre a área é possível visualizar como as particularidades do local iam de encontro ao principal interesse de Boas no momento: o estudo dos fenômenos da mudança cultural (Boas, 2004b), ponto que retomarei mais adiante.

Pela forma como está organizado o índice, em um primeiro momento, pensei se tratar de uma obra de compilação de histórias, com pouco espaço para a descrição do processo através do qual os contos foram coletados. Foi uma surpresa perceber que a obra possuía descrições detalhadas do contato de Hurston com os contadores das histórias. A autora inicia o livro destacando o quanto ficou satisfeita quando lhe deram a tarefa de coletar o folclore dos negros: aquelas histórias que ouvia desde o "mais tenro balançar de seu berço" (Hurston, 2008 [1935]:

\footnotetext{
${ }^{10}$ Como se verá ao longo dessa sessão, um dos principais recursos utilizados pela autora na construção de sua narrativa é a variação do formato da linguagem utilizada na escrita. A autora ora usa o inglês culto, ora usa o "dialeto dos negros" (Jump at the Sun, 2008), buscando reproduzir o modo de falar da população afro- americana do Sul. Considerando a importância de divulgar a obra da autora e a inexistência de uma versão do livro Mules and Men em português, ao longo do texto, traduzo livremente os trechos citados onde a autora faz aparecer na escrita diferentes modos de fala, mas opto por deixar no corpo do texto os trechos em sua versão original para que o recurso literário mobilizado pela autora no idioma original receba o destaque merecido.
}

N.E. Uma versão alinhada de todas as traduções apresentadas no texto pode ser conferida no material complementar ao fim do ensaio. 
1). Desde o início, a autora faz questão de pôr em evidência sua familiaridade com o material que pretendia coletar. Ela afirma que:

[Aquele projeto] "soava para mim como uma camisa apertada. E eu não podia ver que eu a estava vestindo justamente porque eu a estava vestindo. Foi só quando fui para a faculdade, longe de meu ambiente nativo, quando eu pude me ver como outra pessoa e me distanciar, que eu pude me dar conta de minha própria roupa. E eu precisei ter os óculos de espião da antropologia para que eu pudesse observar através dela” (Hurston, 2008 [1935]: 1, tradução livre)

Esse trecho permite considerar mais uma vez o quanto Hurston estava marcada pela concepção boasiana de Antropologia, a qual pressupunha que o distanciamento e a objetividade na condução do trabalho de campo eram os principais recursos que permitiriam ao antropólogo enxergar aquilo que os nativos não podiam ver. Ela destaca que somente após possuir os "óculos de espião" da Antropologia conseguiu entender o que representavam e quão importante eram as histórias que ouvia durante a infância. Hurston faz referência à sua formação acadêmica na disciplina para situar sua posição enquanto antropóloga no contexto de realização daquele trabalho, mas como já destacamos, isso não seria suficiente para que seu livro fosse recebido enquanto uma obra antropológica.

Em seguida, ela explica por que escolheu sua cidade natal, Eatonville, no estado da Flórida para fazer a coleta do material. Hurston (2008 [1935]: 2) afirma que "não escolheu retornar para que todos pudessem admirá-la pelo fato de ter estudado no Norte e voltado pra casa com um diploma e um Chevrolet”, até porque, segundo ela, esses itens não fariam diferença. Ali, ela era Zora, a filha da Lucy e não importa o que tivesse feito, pois ali sempre seria somente a Zora. Ela afirma que quando Boas perguntou onde gostaria de realizar o trabalho, ela se apressou em escolher Eantoville porque sabia que "a cidade era cheia de material e que ali poderia coletar as histórias sem mágoa, dano ou perigo" (Hurston, 2008 [1935]: 2). Ela recorre às suas memórias enquanto criança para destacar o quanto o hábito de contar histórias perpassava o cotidiano dos moradores da cidade e assim afirmar a sua certeza de que ali era um local onde encontraria o material que estava procurando.

Adiante, Hurston fala brevemente sobre as dificuldades em fazer o trabalho de coleta do folclore, afirmando que as "melhores fontes geralmente se encontram em lugares onde há menos influência externa, sendo geralmente pessoas desprivilegiadas, que são as mais tímidas” (Hurston, 2008 [1935]: 2). Essa observação nos permite pensar nas razões que levaram Hurston a considerar o quanto uma abordagem que destacasse a diferença existente entre ela e a população negra da qual era considerada como membro poderia ser prejudicial na condução da pesquisa. Nessa parte inicial, o que chama atenção na descrição de Hurston é que, apesar do fato 
de ter destacado a necessidade do afastamento para que pudesse olhar para o seu ambiente nativo através da "lente de observação" da Antropologia, a autora se refere aos negros e a tudo o que se relaciona à sua vida e seu comportamento em relação aos brancos utilizando o pronome nós, afirmando continuamente sua posição de fala como membro do grupo.

Ao longo de toda a obra, Hurston descreve a si mesma falando no "dialeto dos negros" com seus interlocutores. A meu ver, esse é um recurso narrativo utilizado pela autora para definir as fronteiras do grupo distintivo do qual faz parte: utiliza a escrita do inglês tal qual o modo de falar do sul dos Estados Unidos, tanto fazendo referência ao sotaque bastante marcado da região, quanto a expressões do cotidiano impossíveis de traduzir para o português sem alguma perda no sentido. Esse ponto merece bastante destaque, pois segundo Cheryl Wall, crítica literária afro-americana, (Jump at the Sun, 2008), "a crença da época era que os negros não sabiam falar o inglês corretamente”, e em um contexto de forte segregação racial como o da época, esse dado ganhava grande importância na demarcação de fronteiras raciais e, consequentemente, para a manutenção de relações de pertencimento. Então, quando Hurston opta por transmitir através da escrita essa forma de falar - o "dialeto dos negros"11 - ela evidencia, mais uma vez, o quanto seu pertencimento ao grupo foi essencial para a realização do trabalho, na medida em que a compreensão da língua definitivamente foi um dos elementos que "permitiu que os seus companheiros de infância a aceitassem como um deles” (Boas, 2008: 2). Esse recurso também permitiu marcar seu lugar de fala enquanto pesquisadora através do contraste propiciado pelo uso do inglês culto em sua descrição.

Em Eatonville, boa parte das histórias são coletadas durante conversas no alpendre do único estabelecimento comercial da cidade. A loja é o primeiro lugar que Hurston para quando chega à cidade e ali é imediatamente reconhecida por amigos antigos que ficam muito curiosos em saber o que a trouxe de volta. Como podemos observar no trecho abaixo:

Ao cruzar a linha de entrada no município Maitland-Eatonville, pude ver um grupo na varanda da loja. Fiquei encantada. A cidade não havia mudado. Mesmo amor pela conversa e pela música (...)

'Olá, rapazes,' eu os saudei, enquanto colocava o carro em ponto morto.

Eles tiraram os olhos do jogo e, por um momento, pareceu que haviam se esquecido de mim. Então B. Moseley disse: 'Bem, se não é Zora Hurston!' (...) 'Vai ficar por um tempo, Zora?'

'Sim. Alguns meses.' (...)

\footnotetext{
${ }^{11}$ Expressão utilizada no documentário Jump at the Sun (2008) para identificar o modo de fala corrente na região onde Hurston realizou sua pesquisa.
} 
'Olá, coração! - gritou o prefeito Hiram Lester enquanto subia a rua correndo - Ouvimos muito falar sobre você e sua vida no Norte. Você voltou para casa de vez agora, espero eu

'Não. Vim coletar algumas velhas histórias e contos e eu conheço cês tudo e sei que cês sabe um monte delas. Por isso vim correndo pra casa" (...)

'Como assim, Zora? Cê fala daquelas velhas mentiras que contamo quando tamos apenas sentados aqui na varanda da loja fazeno nada?”, perguntou B. Moseley (...)

'Elas são muito mais valiosas do que você imagina. Queremos guardá-las antes que seja tarde demais '.

'Tarde demais pra quê?'

'Antes que todo mundo as esqueça'

(Hurston, 2008 [1935]: 7-8, tradução livre).

Nesse trecho da conversa novamente é possível vislumbrar a influência do pensamento do Boas nas questões de Hurston. Quando ela afirma a importância de coletar as histórias - as "mentiras", como asseveram seus interlocutores ao longo de toda a obra - chamando atenção para o perigo de seu desaparecimento, posiciona no pano de fundo de suas formulações a ideia de aculturação (Boas, 1920): uma das marcas da antropologia boasiana. Em sua proposta teórica, Boas defende que o principal objetivo da antropologia norte-americana deveria ser o estudo da história cultural e dos fenômenos dinâmicos da mudança cultural (Boas, 1920). Ao constatar que, a partir da aplicação do método histórico que propõe, "todas as formas culturais aparecem, com maior frequência, num estado de fluxo constante e sujeitas a modificações fundamentais" (Boas, 1920: 45), Boas define a aculturação como um fenômeno a partir do qual os elementos estrangeiros são remodelados segundos os padrões que prevalecem em seu novo ambiente. Essa remodelagem através do contato e da troca - atravessada por uma série de outros fatores externos às culturas e marcada pelas particularidades da história cultural de cada grupo segundo a perspectiva de Boas, poderia determinar que certos costumes deixassem de existir. Por isso, a importância de registrá-las "antes que fosse tarde demais", como destacou Hurston. O trabalho de campo e de coleta era entendido na chave da urgência e do salvacionismo. ${ }^{12}$

\footnotetext{
${ }^{12}$ Nos limites dessa seção, proponho uma leitura do livro Mules and Men explorando o diálogo da autora com as teorias antropológicas de sua época. Sobre este ponto específico da urgência do registro, no entanto, me parece importante mencionar que, segundo Cotera (2008), o interesse de Hurston pelo folclore não se dava apenas em função do diálogo que ela buscava construir com Franz Boas. Nesse momento, os registros do folclore e da cultura popular negra também expressavam uma dimensão política e ativista. No contexto do Movimento New Negro do Harlem Renaissance, onde Hurston estava inserida, esses e outros registros da cultura vernacular negra eram
} 
A maior parte da descrição do período em que Hurston permaneceu em Eatonville tem como contexto os encontros cotidianos na loja. No texto, chama a atenção o uso de expressões que põe em evidência a familiaridade da autora com a rotina do lugar. Em Eatonville, as pessoas vinham procurá-la para contar as "mentiras" que ela queria ouvir e ela as transcreve no desenrolar das conversas que estabelecia. No livro todo não há nenhuma história transcrita fora de contexto. Em muitos momentos, Hurston narra que as pessoas simplesmente diziam que era sua vez de contar uma "mentira" e em seguida insere a transcrição da história escolhida pelo contador voluntário. Nesse movimento de situar o contexto das narrativas “coletadas", Hurston também deixa transparecer como o tema das histórias muda conforme as situações paralelas que estivessem acontecendo na cidade no momento. Por exemplo, em um determinado momento da conversa no alpendre da loja, Hurston descreve que é possível ouvir a pregação que está acontecendo na igreja. A partir daí, os presentes começam a conversar sobre religião e logo várias pessoas começam a lembrar de histórias sobre a igreja.

Além disso, também fica claro desde o início que o interesse de Hurston extrapolava às histórias. Ela está o tempo todo atenta aos jogos, às brincadeiras das crianças e às músicas cantadas no local. E o seu interesse pela música é a principal razão que a leva Hurston a seguir viagem para continuar a coleta de material em outro local. Enquanto ela observa às crianças brincarem, um amigo vem se juntar a ela e lhe pergunta por que não vai para "Polk Country"13, o lugar certo para ouvir as melhores "mentiras" e onde todas as canções foram feitas.

Claro, Zora, cê não tá no lugar certo para ouvir as melhor mentira. Porque cê não dá umas voltas lá por Bartow, Lakeland em Polk Country? Lá que eles mente que é uma beleza e é onde fizeram essas música tudo e outras coisas assim. (Hurston, 2008 [1935]: 55, tradução livre)

\section{Uma coleta "situada" do folclore: sobre histórias entre lugares e uma escrita encarnada}

O livro Mules and Men é marcado por diversos debates da antropologia norte-americana da época, mas contrastava com o quadro geral em um ponto fundamental: o pressuposto de uma relação de trabalho que deveria prezar pelo distanciamento e pela objetividade. Sua proposta de trabalho de campo "em casa" e em grupo do qual poderia ser considerada "nativa" desestabilizava o binário Eu/outro prezado no período. Isso, somado ao estilo narrativo conscientemente adotado por Hurston no texto, a fez ir de encontro às convenções da época sobre o que deveria

mobilizados em um processo de reconstrução e autoafirmação da identidade negra afro-americana. Para mais detalhes sobre esse debate, ver Cotera (2021)

${ }^{13}$ Polk County é um condado do Estado da Flórida. Lakeland é uma das cidades localizadas no condado. A divisão em condados corresponde a uma divisão administrativa utilizada em vários estados norte-americanos. 
ser o trabalho antropológico e sobre como deveriam ser as monografias etnográficas (Cotera, 2021) ao produzir uma coleta situada ${ }^{14}$ do folclore. Em um contexto pouco receptivo a inovações - sobretudo, obviamente, àquelas pautadas por uma mulher negra (Lacerda; Parreiras, 2021) -, houve pouco espaço para que o livro fosse bem recebido.

Todo o processo de trabalho de Hurston é marcado por uma dimensão encarnada e o corpo da própria autora povoa a narrativa em diferentes camadas. No decorrer da pesquisa, ela aborda sua trajetória enquanto mulher negra e demonstra como o fato de ser quem era atravessava não só a etapa de realização do trabalho de campo propriamente dita, mas a construção do livro como um todo. Ter o mesmo corpo negro que seus interlocutores não era uma dimensão acessória em seu processo de reflexão, mas uma dimensão crucial do trabalho, onde memórias e experiências compartilhadas definiam um universo particular de possibilidades relacionais, centrais à realização da pesquisa e a forma particular como ela a realizou. Nessa seção, retomo mais algumas outras cenas do livro para que se possa colocar ainda mais em evidência a densa narrativa autorreflexiva de Hurston, impensável para a antropologia da época.

No capítulo 4, Hurston descreve sua chegada à cidade de Loughman em Polk County e há um longo trecho do livro dedicado à descrição de como Hurston conseguiu se aproximar das pessoas para coletar as histórias no lugar. A viagem até lá foi feita de carro - o Chevrolet que a autora mencionou no início. Havia uma grande empresa madeireira na cidade e assim que Hurston chegou ao local, a primeira sinalização que viu foi uma placa com o nome da empresa. Então, ela entra na área da madeireira para procurar hospedagem e logo à frente encontra duas mulheres que indicam onde ela pode conseguir um quarto. Ao chegar ao local indicado por elas, Hurston descreve que

Naquela noite o lugar estava cheio de homens (...). Muito pouco foi dito diretamente a mim e quando tentei ser amigável me deparei com uma disposição perceptível para me rechaçar. Isso me preocupou porque eu vi imediatamente que este grupo de várias centenas de negros vindos de todo o Sul seria um campo rico para o trabalho de coleta do folclore, mas aqui estava eu figurativamente morrendo de fome no meio da abundância. (Hurston, 2008 [1935]: 60, tradução livre)

\footnotetext{
${ }^{14}$ O termo "situado" mobilizado nessa seção tem como referência o debate sobre subjetividade, posicionalidade e parcialidade na prática antropológica, que ganharia força na disciplina vários anos após a publicação de Mules and Men. Nessa seção, utilizo livremente o termo situado para significar a forma de investigação de Hurston de modo a destacar a dimensão precursora de sua etnografia. No livro, a autora não se refere a sua pesquisa dessa maneira.
} 
Logo ela entenderia que mais uma vez os informantes se fechavam intimidados pelo que poderia representar uma "mulher pomposa como ela" viajando sozinha de carro pela área. O problema nessa primeira abordagem em Loughman foi que todos pensaram que Hurston deveria ser "algum tipo de detetive" (:60) e, quando mais à frente, ela descreve que Polk County era conhecido por ser o refúgio de foragidos da justiça, não fica difícil de entender por que ela não estava conseguindo conversar com ninguém. Ela narra suas estratégias de abordagem ao longo de todo o livro de uma forma que nos permite visualizar as escolhas conscientes que tomou para conseguir realizar a pesquisa. Em Loughman, ela decide mentir dizendo que também era uma foragida da justiça e assim consegue ser aceita pelo grupo que logo começaria a contar muitas outras "mentiras" para o seu trabalho.

Ela narra que nos dias de pagamento havia sempre grandes festas no local e na primeira que pôde acompanhar utilizou outra estratégia para conseguir se aproximar e ser aceita: permitiu que os homens a cortejassem. A partir daí todos começam a ficar mais confortáveis com sua presença. Mas é somente quando Hurston aceita subir ao palco para cantar uma das músicas com a banda da festa que definitivamente alcança seu objetivo. Ela conta que:

Quando a música acabou, antes que Joe Willard me tirasse do palco, eu sabia que agora eu fazia parte do círculo de confiança. Eu primeiro tive o trabalho de convencer que eu não era um inimigo na questão da lei; e, em segundo lugar, eu tive que provar que eu era gente como eles (...)

Depois disso, meu carro se tornou o carro de todos. (Hurston, 2008 [1935]: 65, tradução livre)

A partir desse momento, Hurston transcreve muitas histórias. Nos capítulos 5, 6, 7 e em parte do capítulo 8 se ouve pouco a própria voz da autora no texto e a vemos presente somente na descrição das conversas em que as histórias eram contadas, seguidas de sua transcrição. Grande parte delas foram coletadas em conversas durante um dia em que Hurston pôde acompanhar os trabalhadores até a floresta para a coleta de madeira e em um dia de folga em que os acompanhou até uma pescaria. Muitas delas relatadas em meio a situações jocosas, deixando evidente sua aproximação ao grupo.

Em sua descrição cuidadosa do processo de aproximação e conquista de confiança dos locais em Polk County, é como se Hurston antecipasse o recurso narrativo mobilizado por Geertz (1989), muitos anos depois, em sua clássica descrição sobre como uma fuga conjunta de uma ação da polícia em Bali o permitiu 'ser aceito' pelos locais, garantindo assim que ele pudesse dar continuidade à sua pesquisa sobre a briga de galos na região. Mas, diferentemente de Geertz, onde a narrativa da aceitação - considerada 'inovadora' naquele momento por trazer ao texto as visões dos 'nativos' sobre o antropólogo - se transforma em um relato de fundo que autoriza o 
pesquisador a desaparecer do texto na narrativa que se segue, Hurston mobiliza análises e descrições sobre as negociações e sobre os efeitos de sua presença em campo quase que transversalmente ao longo da obra. Utilizando-se do que ela mesma define de "histórias entre os lugares", e afastando-se dos modelos de monografia etnográfica comuns à época, centrados na análise das questões culturais de interesse que perpassavam as histórias coletadas (Cotera, 2021), Hurston traz ao texto elementos narrativos que expõem a relação de pesquisa em sua dimensão de negociação e, de forma despretensiosa, acaba por deixar transparecer em sua descrição como as relações estabelecidas em campo eram necessariamente atravessadas pela movimentação de processos contínuos de diferenciação.

Ao narrar seu processo de aproximação à comunidade de Loughman, Hurston deixa claro como sua identidade racial comum a seus interlocutores, exclusivamente, não seria suficiente para constituir uma relação imediata de confiança. Havia muitos outros fatores a serem levados em consideração e ela precisou mobilizar estratégias para administrar conscientemente dimensões de sua trajetória que a diferenciavam do grupo. Vista como uma "mulher pomposa" que despertava uma série de desconfianças, Hurston incorpora suas reflexões sobre si mesma ao texto, evidenciando como seu corpo negro, seu modo de falar, de vestir, seu carro, seu lugar de mulher viajando sozinha trouxeram diferentes desafios, em diversas situações.

Ainda tratando sobre as formas como o corpo perpassa a narrativa de Hurston, recupero alguns elementos da segunda parte do livro, onde a autora apresenta o material coletado sobre o Vodu. Para cumprir com essa parte do trabalho, Hurston segue para Nova Orleans, "a capital americana do Vodu" (Hurston, 2008 [1935]: 183, tradução livre), localizada no Estado de Louisiana. Os sete capítulos seguem um roteiro comum. As sessões são dedicadas a descrever as relações que Hurston estabeleceu com sete doutores do Vodu da cidade de Nova Orleans. Nessa segunda parte, há uma narrativa menos fluida entre os capítulos, na medida em que Hurston descreve individualmente, em cada um deles, a relação que estabeleceu com cada um dos doutores. Nesse ponto, a descrição detalhada dos rituais realizada pela autora ganha outra profundidade quando Hurston narra como conseguiu acessá-los. Ela realizou rituais de iniciação com cada um dos sete doutores e, a partir daí, como integrante do culto, passa a descrever não só os rituais que pôde presenciar como aprendiz, mas também os que pôde realizar, radicalizando, desde outro lugar, sua forma de trabalho e de escrita encarnada, contrastiva com as ficções de objetividade e distanciamento da antropologia do período.

Assim, o trabalho de Hurston com suas estratégias narrativas "fora de época” - após a insistência da autora para que seu orientador escrevesse o prefácio ${ }^{15}$ - seria situada por Boas

\footnotetext{
${ }^{15}$ Hemenway (1980), outro biógrafo de Hurston, transcreve em seu livro uma carta da escritora à Boas na qual ela o convida a prefaciar o livro Mules and Men, insistindo para que ele aceitasse, mesmo sabendo que o livro não cumpria com os critérios de objetividade estabelecidos por ele.
} 
como uma contribuição ao campo de pesquisa sobre o folclore e caracterizada como uma “contribuição não usual ao nosso conhecimento da vida interior dos negros” (Boas, 2008: ix). Ele destaca positivamente o fato de Hurston ter conseguido acessar a "configuração íntima da vida social dos negros, o que nunca havia sido atingido anteriormente" (:ix) por nenhum pesquisador branco. Surpreendentemente, Boas parece não avaliar com maus olhos o fato de Hurston ter escolhido realizar o trabalho de coleta na cidade em que nasceu e afirma que um dos seus maiores méritos foi conseguir ser aceita pelos seus companheiros de infância como um deles. Ele a parabeniza por ter sido capaz de penetrar por dentro aquele comportamento afetado pelo qual "o negro exclui o observador branco de participar efetivamente em sua verdadeira vida interior" (:ix) e aponta como um grande feito a forma como Hurston conseguiu ganhar a confiança dos doutores do Vodu. No entanto, a resistência de Boas e seus pares aos métodos heterodoxos de sua aluna logo ficariam mais claras e seria decisiva em eventos que marcariam profundamente a trajetória de Hurston. Mesmo prefaciado por Boas, Mules and Men, livro produzido fazendo uso dos "óculos de espião da antropologia" e escrito por uma autora formada sob a orientação de um dos maiores antropólogos do período, não foi entendido como um trabalho digno do reconhecimento da comunidade acadêmica da época.

\section{Entre histórias e teorias: a relação ambivalente com Franz Boas}

Partindo da noção de que o tornar-se nativo tem sido um dos fetiches do fazer antropológico ao longo do tempo, a avaliação de Boas acerca dos méritos de Hurston em ser aceita como parte do grupo poderia soar como um argumento a contribuir para que a obra da autora fosse recebida como uma contribuição de valor ao campo da Antropologia. Mas, como veremos, as percepções de Boas sobre o que fosse um uso adequado do material empírico em estudos antropológicos pressupunham um método bastante particular. Nesse ponto, é preciso ter em conta as questões próprias à antropologia da época e a centralidade do debate em torno do folclore naquele contexto.

O interesse de Boas pelas pesquisas sobre o tema do folclore pode ser remontado a um período bastante anterior. Em 1883, Boas foi para as Ilhas Baffin no Ártico para realizar um estudo geográfico sobre um grupo chamado Innuit e, segundo especialistas em sua obra, foi a partir dessa experiência que fez sua transição das ciências exatas para a ciência descritiva (Muller-Willer, 2014) e "acabou virando etnólogo” (Silverman, 2005: 260). Nesse momento, os interesses de Boas estavam muito marcados pela sua formação em geografia e seu principal objetivo era entender as relações entre o homem e o meio ambiente. Ele trabalhava com a hipótese de que a distribuição populacional, os movimentos migratórios, os tipos de fixação, as rotas de viagem e o uso das fontes renováveis eram influenciados pelas flutuações de temperatura das condições naturais do meio ambiente do ártico. Foi a partir do interesse de Boas pelo tema das migrações que ele passou a reconhecer o valor da transmissão oral de histórias, 
tradições e crenças religiosas (Muller-Willer, 2014) como fontes importantes. As histórias seriam um meio para compreender os padrões de fixação e migração. Mas para melhor demonstrar onde o Folclore se encaixa na proposta teórica de Boas, passemos à descrição de um de seus textos mais importantes: "As limitações do método comparativo em Antropologia" (1896).

Ao longo de todo o texto, Boas faz duras críticas ao método comparativo usado pelos antropólogos evolucionistas. Ele inicia destacando que os antropólogos do mundo moderno constataram que a sociedade humana por toda parte possuía traços fundamentais em comum, mas que a partir da observação da existência desses traços culturais similares entre os povos, iniciou-se uma controvérsia. Como explicar essas similaridades? Os evolucionistas culturais apresentavam a seguinte resposta a essa questão. Para Tylor (2005: 69), "essa uniformidade que tanto permeia a civilização" poderia "ser atribuída, em grande medida, à ação uniforme de causas uniformes” e os diferentes comportamentos, costumes e crenças - divididos em graus representariam "estágios de desenvolvimento ou evolução". O modelo do evolucionismo cultural estava atrelado à aposta da existência de uma origem comum e ao pressuposto de que haveria conexões históricas entre os mais variados povos do mundo. Ao longo de seu texto, Boas argumenta a favor de desmontar essas formulações.

A principal diferença entre a proposta de Boas e a dos evolucionistas culturais se dava pelo fato de que os últimos acreditavam que um fenômeno etnológico só poderia se desenvolver em vários lugares diferentes a partir das mesmas causas. Boas não concordava e defendia que o pressuposto mais aceitável era que "o desenvolvimento histórico pode ter seguido cursos variados" (Boas, 2004: 33). Então, em vez de supor causas comuns, para Boas, era necessário investigar as causas a partir das quais os fenômenos se desenvolveram. Boas concorda que existam leis governando o desenvolvimento da cultura humana, mas destaca que o objetivo da investigação deve ser "descobrir os processos pelos quais certos estágios culturais se desenvolveram" (Boas, 2004: 33). Ressalta que "os costumes e as crenças, em si mesmos, não constituem a finalidade última da pesquisa” (2008 [1935]: 33), pois o que interessa saber são as "razões pelos quais tais costumes e crenças existem" (:33): "descobrir a história de seu desenvolvimento" (:33). Mas discorda que o método empregado pela antropologia evolucionista tenha fornecido respostas satisfatórias a essa questão, pois entende como um erro supor a existência de conexões históricas a priori. Para Boas, é preciso haver uma base para supor tal conexão. Essa base só seria fornecida pelos dados empíricos e isso fica claro quando descreve sua proposta de método.

O estudo detalhado de costumes em sua relação com a cultura total da tribo que os pratica, em conexão com uma investigação de sua distribuição geográfica entre tribos vizinhas, propiciaria quase sempre um meio de 
determinar com considerável precisão as causas históricas que levaram à formação dos costumes em questão e os processos psicológicos que atuaram em seu desenvolvimento. (Boas, 2004: 33)

Então, se compreendermos as histórias folclóricas como um meio para acessar crenças e costumes fica mais fácil entender como elas poderiam ser utilizadas para acessar a história cultural de um determinado grupo. Mas os anseios de Boas pelo entendimento dos processos e das mudanças ultrapassavam os limites sincrônicos dos estudos empíricos da cultura e alcançavam até os tempos mais antigos, os quais poderiam ser acessados através de dados da biologia, da arqueologia e da geografia. Se nos atentarmos que um dos passos metodológicos defendidos por Boas era a necessidade de considerar estes mesmos costumes e crenças em relação ao todo da cultura e da história cultural do grupo, é possível vislumbrar algumas das outras razões para que Mules and Men não tenha atendido aos "critérios" do antropólogo. Em um prefácio elogioso ao trabalho "pouco usual" (Boas, 2008: ix) de coleta do folclore conduzido por Hurston, é quase como se Boas afirmasse que, em sua obra, os costumes e as crenças, em si mesmos, constituem a finalidade última da pesquisa (Boas, 2004) e que a análise e o diálogo com a teoria da antropologia cultural, portanto, estariam por ser feitas por outros. Envolvido na busca por consolidar a antropologia como uma ciência autônoma, com métodos e conceitos próprios, Boas parece tratar os registros etnográficos de Hurston como puro e simples material bruto - um quadro que ganha outro tom quando lembramos como a institucionalização do campo dos estudos antropológicos nos EUA também seria marcada por um movimento de diferenciação ao campo dos estudos folclóricos. Ciente do envolvimento de Hurston com o movimento cultural do Harlem, com seu prefácio sintético que põe em destaque a heterodoxia da obra, Boas parece querer sugerir que aqueles escritos poderiam ser melhor aproveitados no universo da literatura e da cultura popular.

Para finalizar, ainda em relação a Boas, gostaria de destacar outro ponto que acredito ser importante para entendermos em que bases se dava a relação estabelecida com sua aluna, Zora Hurston. Silverman (2005) nos lembra que quando Boas publica o hoje "clássico" texto "As limitações do método comparativo" (1896), havia cerca de dez anos que o antropólogo havia se mudado permanentemente para os Estados Unidos e que este ainda estava firmando sua base institucional na Universidade de Columbia. Na época, o centro dominante de produção antropológica nos Estados Unidos se centrava em Washington, onde predominava uma tradição evolucionista e racialista (Silverman, 2005). Eram muitas as divergências entre Boas e os antropólogos desses centros, principalmente em relação ao seu posicionamento frente a questões políticas referentes às relações raciais no país (Silverman, 2005). Boas fez vários pronunciamentos públicos sobre a questão a partir do início do século XX (Stocking Jr, 2004). 
É importante não perder de vista que foi nesse contexto de disputa que Boas publicou "As limitações do método comparativo em Antropologia”.

O conceito de cultura que Boas tratava de adensar se colocava como um conceito para substituir o de raça e, tal como nos lembram Bourdieu (1983), Foucault (2005) e Hymes (1974), não podemos perder de vista que a disputa pelo domínio teórico em um campo não se limita aos debates científicos por si só. À luz das reflexões de hooks (1990), penso que é importante pensar na relação ambivalente existente entre Zora Hurston e Franz Boas sem perder de vista as tensões políticas em torno do debate sobre o racismo nos EUA de então. hooks (1990) sugere que o interesse de Boas pelo trabalho de Hurston ia além das possibilidades de uso acadêmico do material de coleta de folclore que a escritora poderia coletar, o que, por si, tem sido alvo de críticas por caracterizar uma relação de trabalho que reificaria hierarquias e dificultaria o reconhecimento merecido ao trabalho acadêmico de Hurston. Ser o orientador da primeira aluna negra da Universidade de Barnard se tornou um caminho para que Boas afirmasse uma posição política e galgasse espaço em um meio acadêmico onde estava buscando colocar teorias dominantes em disputa. Segundo hooks (1990), o projeto de Boas de questionar as teorias racistas que dominavam o meio acadêmico em sua época o fez mais do que um orientador para Hurston. A relação entre os dois o dotou de uma posição de "aliado", "estratégica” para Boas em muitas dimensões. Esse elemento não impediu, no entanto, que o antropólogo duvidasse do potencial de Hurston como pesquisadora e rechaçasse sua forma de trabalho e escrita, o que resultou em uma carta de indicação negativa à candidatura de sua ex-orientanda a uma bolsa para cursar o doutorado em antropologia na Universidade de Columbia. Segundo Cotera (2021), após ser indicado por Hurston como uma referência que corroboraria sua candidatura, Boas apresentou uma "carta de recomendação concisa" (:162), onde destacava que apesar de considerar Hurston uma "observadora muito boa... capaz de obter a confiança das pessoas" (:162), a metodologia que ela empregava era "mais jornalística que científica” (:162) e que ele não estava "com a impressão" de que ela tinha "o calibre certo para uma bolsa de estudos em Guggenheim" (: 162).

\section{Considerações finais}

"Pesquisa é curiosidade formalizada. É cutucar e se intrometer, só que com um propósito" (Hurston, 2010 [1942]: 211)

A obra Mules and Men não foi reconhecida enquanto uma contribuição à altura pela comunidade antropológica de sua época. Fortemente marcada pela presença do eu autoral de Hurston, foi considerada subjetiva demais para ser entendida como ciência social (Boxwell, 1992). Ironicamente, o livro acabou por antecipar com maestria debates que tensionariam o 
campo antropológico anos depois (Cotera, 2021; Böschemeier et al, 2020). A partir da década de 80, no marco do que ficou conhecido como virada pós-moderna (Clifford; Marcus, 2016), vimos questões sobre a subjetividade em campo ganhar centralidade nos debates sobre o fazer antropológico e observamos escritas etnográficas autorais e posicionadas serem apresentadas como um caminho para tensionar e explicitar criticamente a relação hierárquica desigual estabelecida pelos antropólogos com seus interlocutores. Concomitantemente, as interpelações vindas do feminismo e, sobretudo, dos questionamentos apresentados no bojo das críticas levantadas pelo feminismo negro (Hill Collins, 2012), trouxeram para o centro do debate a necessidade de levarmos em conta os múltiplos marcadores sociais da diferença que compõem as matrizes de desigualdade que atravessam a experiência de mulheres racializadas, em um movimento que buscou pautar como o apagamento da obra de Zora Hurston e aàs dificuldades enfrentadas em sua trajetória intelectual estiveram marcadas pelo racismo e pelo sexismo.

Penso que a disputa em torno da classificação da obra Mules and Men ao longo do tempo é bastante reveladora da pluralidade de caracterizações que perpassam a Antropologia e a etnografia ao longo de sua história. A ideia corrente e bastante disseminada de que certos períodos da história e teoria da Antropologia só podem ser compreendidos pela leitura de alguns trabalhos "indispensáveis” contribui para reforçar as relações de poder hegemônicas que pautam a definição do que e quem podem ser reconhecidos como [produção] intelectual digna de nota, colaborando para a manutenção de matrizes históricas de desigualdade no meio acadêmico. Certamente, é longo o caminho para que Mules and Men possa ocupar uma posição equivalente no quadro de leituras canônicas apresentadas no decorrer do processo formativo em antropologia, mas sugiro que poderia e deveria. Nesse ensaio, apresentei um exercício de reflexão buscando indicar a forma como a obra dialogava com as teorias de seu tempo e recuperar elementos do processo que determinou que não fossem reconhecidas as contribuições oferecidas pelo livro ao campo da antropologia da época. Espero que o exercício de leitura elaborado possa auxiliar na produção de caminhos para que possamos adensar o entendimento da teoria antropológica clássica e de determinados períodos da história da disciplina, fazendo jus às contribuições de intelectuais negras nas discussões sobre o nascimento e consolidação da disciplina.

\section{Referências Bibliográficas}

BASQUES, Messias. 2019. Zora Hurston e as luzes negras das Ciências Sociais (Texto de apresentação). In: Ayé: Revista de Antropologia, v. 1, n. 1.

BOAS, Franz. 2004. “As limitações do método comparativo da Antropologia”. In: CASTRO, Celso. (org.) Antropologia Cultural. Rio de janeiro: Jorge Zahar. p. 25-52. 
BÖSCHEMEIER, Ana Gretel et al. 2020. A tradução de Zora Neale Hurston para o cânone antropológico: Práticas de extensão desde uma perspectiva feminista e interseccional. Mutatis Mutandis. Revista Latinoamericana de Traducción, v. 13, n. 2, p. 228-254. DOI 10.17533/udea.mut.v13n0a02

BOURDIEU, Pierre. 1983. “O campo científico”. In ORTIZ, Renato. (org.). Pierre Bourdieu. São Paulo: Ed. Ática, pp.122-155.

BOXWELL, D. A. 1992. "Sis Cat" as Ethnographer: Self-Presentation and Self-Inscription in Zora Neale Hurston's Mules and Men. African American Review, p.605-61

CLIFFORD, James; MARCUS, George. 2016. A escrita da cultura: poética e política da etnografia. Rio de Janeiro: Papéis Selvagens/edUFRJ.

COTERA, María Eugenia. 2021. Inventando a Nação: Zora Neale Hurston e os usos do folclore. Ayé: Revista de Antropologia, edição especial (Fire!!!Textos escolhidos de Zora Neale Hurston):137-180.

FOUCAULT, Michel. 2005. "Sobre a arqueologia das ciências. Resposta ao círculo de epistemologia”. Inc: FOUCAULT, Michel. Arqueologia das Ciências e História dos Sistemas de Pensamento. Rio de Janeiro: Forense Universitária. pp. 82-118.

GEERTZ, Clifford. 1989. "Um jogo absorvente: notas sobre a briga de galos balinesa”. In GEERTZ, Clifford. A interpretação das culturas. Rio de Janeiro: LTC, pp 278-321,

GOMES, Heloisa Toller. 2004. Visíveis e invisíveis grades: vozes de mulheres na escrita afrodescendente contemporânea. Caderno Espaço Feminino, v. 12, n. 15.

HEMENWAY, Robert E. 1980. Zora Neale Hurston: a literary biography. Illinois: University of Illinois Press.

HILL COLLINS, Patricia. 2012. "Rasgos distintivos del pensamiento feminista negro”. In: JABARDO, Mercedes. (ed). Feminismos negros: una antologia. Madrid: Traficante de sueños, pp. 99-134.

hooks, bell. 1990. "Saving Black Folk Culture: Zora Neale Hurston as anthropologist and writer"'. In hooks, bell. Yearning: race, gender, and cultural politics. Boston: South end Press. HURSTON, Zora Neale. 2008 [1935]. Mules and Men. New York: Harper Collins.

HURSTON, Zora Neale. 2010 [1942]. Dust Tracks on the road: an autobiography. Harper Collins. HURSTON, Zora Neale. 2019. O que os editores brancos não publicarão Tradução de Messias Basques. In: Ayé: Revista de Antropologia, v. 1, n.1

HYMES, Dell. 1974. “The use of Anthropology: critical, political, persona”l. In: HYMES, Dell. (ed.). Reinventing anthropology. New York, Vintage Books, 1974, pp. 3-79.

JUMP AT THE SUN. The Life of Zora Neale Hurston. Direção: Sam Pollard. Texto/Produção: Kristy Andersen. Bay Bottom News, 2008. Documentário. 84'00”. Transcrição disponível em: http://newsreel.org/transcripts/Zora-Neale-Hurston-Transcript.html. Acesso em 05 de agosto de 2015. 
KOUSSER, J. Morgan. Jim Crow Laws. Dictionary of American History, v. 4, p. 479-480, 2003.

LACERDA, Paula; PARREIRAS, Carolina. Zora Hurston. Campo - um podcast de antropologia. 15 de Março de 2021. Podcast, Áudio, 29'.

LOURENÇO, Vanessa Cândida. Antropóloga, Mulher e Negra: Sobre a trajetória de Zora Neale Hurston. Trabalho de conclusão de curso - Departamento de Ciências Sociais, Universidade de São Paulo, São Paulo, 20

MCKAY, Claude. Harlem: Negro Metropolis. New York: EP Dutton \& Company, inc., 1940

MÜLLER-WILLE, Ludger. The Franz Boas Enigma. Inuit, Artic and Sciences. Montréal: Baraka Books, 2014.

RAMPERSARD, Arnold. 1997. "Introduction”. In: LOCKE, Alain (ed.). The New Negro. Nova York: Simon and Schuster.

RAMOS, Ana Carolina; TITONELI, Bruner; SAFATLE, Yasmin; Marina Fonseca. Zora Hurston e as negras antropologias. 28 de setembro de 2020. Podcast, Áudio, 55'.

SILVA, Fernanda Felisberto da. Escrevivências na Diáspora: escritoras negras, produção editorial e suas escolhas afetivas, uma leitura de Carolina Maria de Jesus, Conceição Evaristo, Maya Angelou e Zora Neale Hurston. Tese de Doutorado - Instituto de Letras, Universidade do Estado do Rio de Janeiro, Rio de janeiro, 2011

SILVERMAN, SYDEL [et al]. One discipline, four ways: British, German, French and American Anthropology. Chicago: University of Chicago Press, 2005.

STEW ART, Jeffrey C. 2018. The New Negro: the life of Alain Locke. London: Oxford University Press.

STOCKING JR. George. O folclore e a crítica ao evolucionismo. In:___ (org). A formação da Antropologia norte-americana. Rio de Janeiro: Contraponto: Editora UFRJ, 2004.

TYLOR, Edward B. A ciência da cultura. Em: CASTRO, C. (org.) Evolucionismo Cultural. Textos de Morgan, Tylor e Frazer. RJ: Zahar Editor, 2005: pp. 67-100.

WALKER, Alice. In Search of Zora Neale Hurston. Ms. Magazine, 1975. In: HURSTON, Zora Neale. Mules and Men. New York: Harper Collins, 2008 [1935]

OBETO, Débora. Fieldwork Footage: Descobrindo Zora Neale Hurston. ILUMINURAS, v. 21, n. 53, 2020.

\section{sobre a autora}

\section{Telma de Sousa Bemerguy}

É mestra e doutoranda em Antropologia Social pelo Museu Nacional da Universidade Federal do Rio de Janeiro, com graduação também em Antropologia pela Universidade Federal do Oeste do Pará. É pesquisadora vinculada ao Laboratório de pesquisas em etnicidade, cultura e desenvolvimento 
(LACED/Museu Nacional) e ao Núcleo de Estudos sobre Amazônia Contemporânea (NUAMA/UERJ).

Contribuição de Autoria: Não se Aplica

Financiamento: Em seu doutorado, a autora contou com financiamento público via Editais de auxílio-pesquisa do PPGAS/Museu Nacional $(2017,2018,2019)$ e com recursos da IJURR Foundation (Writing-up Grant, 2020).

Recebido em 03/03/2021

Aceito para publicação em 02/06/021 


\section{Material Complementar}

\section{Alinhamento das traduções e textos de partida}

Texto de Partida

It was fitting me like a tight chemise. I couldn't see it for wearing it. It was only when I was off in college, away from my native surroundings, that I could see myself like somebody else and stand off and look my garment. Then I had to have the spy-glass of Anthropology to look through at that
[Aquele projeto] soava para mim como uma camisa apertada. E eu não podia ver que eu a estava vestindo justamente porque eu a estava vestindo. Foi só quando fui para a faculdade, longe de meu ambiente nativo, quando eu pude me ver como outra pessoa e me distanciar, que eu pude me dar conta de minha própria roupa. E eu precisei ter os óculos de espião da antropologia para que eu pudesse observar através dela.

Zora Neale Hurston, Mules and Men, 2008 [1935]: 1

As I crossed the Maitland-Eatonville township line I could see a group on the store porch. I was delighted. The town had not changed. Same love of talk and song (...)

'Hello boys,' I hailed them as I went into neutral. They looked up from the game and for a moment it looked as if they had forgotten me. Then B. Moseley said, 'Well, if it ain't Zora Hurston!' (...)

'You gointer stay awhile, Zora?'

'Yep. Several months.' (...)

'Hello, heart-string,' Mayor Hiram Lester yelled as he hurried up the street. 'We heard all about you up North. You back home for good, I hope' 'Nope. Ah come to collect some old stories and tales and Ah Know y'all Know a plenty of 'em and that's why Ah headed straight for home' (...) 'What you mean, Zora, them big old lies we tell when we're jus' sittin' around here on the store porch doin' nothin" asked B. Moseley. (...)
Ao cruzar a linha de entrada no município Maitland-Eatonville, pude ver um grupo na varanda da loja. Fiquei encantada. A cidade não havia mudado. Mesmo amor pela conversa e pela música (...)

'Olá, rapazes,' eu os saudei, enquanto colocava o carro em ponto morto.

Eles tiraram os olhos do jogo e, por um momento, pareceu que haviam se esquecido de mim. Então B. Moseley disse: 'Bem, se não é Zora Hurston!' (...)

'Vai ficar por um tempo, Zora?'

'Sim. Alguns meses.' (...)

'Olá, coração! - gritou o prefeito Hiram Lester enquanto subia a rua correndo - Ouvimos muito falar sobre você e sua vida no Norte. Você de voltou para casa de vez agora, espero eu ' 'Não. Vim coletar algumas velhas histórias e contos e eu conheço cês tudo e sei que cês sabe um monte delas. Por isso vim correndo pra casa" (...) 


\begin{tabular}{|c|c|}
\hline $\begin{array}{l}\text { 'They are lot more valuable than you might } \\
\text { think. We want to set them down before it's too } \\
\text { late'. } \\
\text { 'Too late for what?' } \\
\text { 'Before everybody forgets all of them" }\end{array}$ & $\begin{array}{l}\text { 'Como assim, Zora? Cê fala daquelas velhas } \\
\text { mentiras que contamo quando tamos apenas } \\
\text { sentados aqui na varanda da loja fazeno nada?”, } \\
\text { perguntou B. Moseley (...) } \\
\text { 'Elas são muito mais valiosas do que você } \\
\text { imagina. Queremos guardá-las antes que seja } \\
\text { tarde demais '. } \\
\text { 'Tarde demais pra quê?' } \\
\text { 'Antes que todo mundo as esqueça elas' }\end{array}$ \\
\hline \multicolumn{2}{|c|}{ Zora Neale Hurston, Mules and Men, 2008 [1935]: 7 e 8} \\
\hline $\begin{array}{l}\text { Course, Zora, you ain't at de right place to git de } \\
\text { be' lies. Why don't you do down ' round Bartow } \\
\text { and Lakeland ' round in dere - Polk country? } \\
\text { Dat's where they really lies up a mess and dats } \\
\text { where dey makes up all de songs and things lak } \\
\text { dat. }\end{array}$ & $\begin{array}{l}\text { Claro, Zora, cê não tá no lugar certo para ouvir as } \\
\text { melhor mentira. Porque cê não dá umas voltas lá } \\
\text { por Bartow, Lakeland em Polk Country? Lá que } \\
\text { eles mente que é uma beleza e é onde fizeram } \\
\text { essas música tudo e outras coisas assim. }\end{array}$ \\
\hline \multicolumn{2}{|l|}{ Zora Neale Hurston, Mules and Men, 2008 [1935]: 55} \\
\hline $\begin{array}{l}\text { That night the place was full of men (...) Very } \\
\text { little was said directly to me when I tried to be } \\
\text { friendly there was a noticeable disposition to fend } \\
\text { me off. This worried me because I saw at once } \\
\text { that this group of several hundred Negroes from } \\
\text { all over the South was a rich field for folk-lore, } \\
\text { but here was I figuratively starving to death in the } \\
\text { midst of plenty }\end{array}$ & $\begin{array}{l}\text { Naquela noite o lugar estava cheio de homens (...) } \\
\text { Muito pouco foi dito diretamente a mim e } \\
\text { quando tentei ser amigável me deparei com uma } \\
\text { disposição perceptível para me rechaçar. Isso me } \\
\text { preocupou porque eu vi imediatamente que este } \\
\text { grupo de várias centenas de negros vindos de todo } \\
\text { o Sul seria um campo rico para o trabalho de } \\
\text { coleta do folclore, mas aqui estava eu } \\
\text { figurativamente morrendo de fome no meio da } \\
\text { abundância. }\end{array}$ \\
\hline \multicolumn{2}{|l|}{ Zora Neale Hurston, Mules and Men, 2008 [1935]: 60} \\
\hline $\begin{array}{l}\text { By the time that the song was over, before Joe } \\
\text { Willard lifted me down from the table I knew } \\
\text { that I was in the inner circle. I had first to } \\
\text { convince the 'job' that I was not an enemy in the } \\
\text { person of the law; and, second, I had to prove that } \\
\text { I was their Kind (...) } \\
\text { After that my car was everybody's car. }\end{array}$ & $\begin{array}{l}\text { Quando a música acabou, antes que Joe Willard } \\
\text { me tirasse do palco, eu sabia que agora eu fazia } \\
\text { parte do círculo de confiança. Eu primeiro tive o } \\
\text { trabalho de convencer que eu não era um inimigo } \\
\text { na questão da lei; e, em segundo lugar, eu tive que } \\
\text { provar que eu era gente como eles (...) } \\
\text { Depois disso, meu carro se tornou o carro de } \\
\text { todos. }\end{array}$ \\
\hline
\end{tabular}

